\title{
Genetic determinants of trimethoprim resistance in a strain of Staphylococcus aureus
}

\author{
L. S. NAKHLA \\ From the Cross-Infection Reference Laboratory, Colindale, London
}

SYNOPSIS Trimethoprim resistance was transduced from a resistant to a sensitive strain of Staphy lococcus aureus by means of a cell-free phage lysate of the resistant strain. The resistance acquired byn the sensitive strain was stable and could not be eliminated by growth at an elevated temperature or ${ }_{0}^{\circ}$ in the presence of acridine or ethidium bromide. This stability and the kinetics of transduction by ultraviolet-irradiated phage suggest that resistance to trimethoprim in Staph.aureus is determined by a chromosomal rather than a plasmid gene.

A recent survey of drug resistance in Staphylococcus aureus cultures isolated from patients in hospitals showed that $1.6 \%$ were resistant to trimethoprim (Nakhla, 1972). All the trimethoprim-resistance strains were also resistant to several other antimicrobial drugs, including sulphonamides. It may be expected that the widespread use of trimethoprim, as in the mixture with sulphamethoxazole known as co-trimoxazole, will result in an increase in the frequency of trimethoprim-resistant staphylococci. Some $20 \%$ of staphylococci isolated in London hospitals in 1970/71 were resistant to sulphonamides.

A sensitive bacterium may acquire drug resistance by spontaneous mutation or by the transfer of genetic determinants (chromosome- or plasmidborne) from a resistant strain. Some strains of bacteria can be readily trained in vitro to trimethoprim resistance, suggesting that resistant mutants arise

\footnotetext{
'Present address: Department of Bacteriology, Westminster Hospital Teaching Group, Queen Mary's Hospital, Roehampton, London, SW15 SPN

Received for publication 26 June 1973.
}

spontaneously at a fairly high frequency (Darrell Garrod, and Waterworth, 1968). As far as is known, the only mechanism of gene transfer between staphylococci is transduction. Attempts were made toge transduce trimethoprim resistance between strax of staphylococci, to determine whether the genefia determinants for resistance are located on the chrom osome or carried on a plasmid. This can be deduced from the transductional kinetics and the stability of the resistance character under different environ-零 mental conditions (Arber, 1960; Hashimoto, Kono, and Mitsuhashi, 1964; Asheshov, 1966, 1969; Rubin윽 and Rosenblum, 1970).

\section{Materials and Methods}

STRAINS OF STAPH. AUREUS

The table lists the strains used in this study with their relevant characters. Strain $71 / 18524$, a naturally. occurring trimethoprim-resistant strain, was used aso donor of this character in transduction experiments. The other strain (PS6), which was trimethoprim-은 sensitive, acted as a recipient in standard transduction $D$ experiments.

\begin{tabular}{|c|c|c|c|c|}
\hline Source & Strain No. & Phage Typing Pattern & $\begin{array}{l}\text { Antibiotic Resistance } \\
\text { Pattern' }\end{array}$ & MIC of $T M(\mu \mathrm{g}$ per $\mathrm{ml})$ \\
\hline $\begin{array}{l}\text { Sputum of a patient with pneumonia } \\
\text { PS6 }^{2}\end{array}$ & $\begin{array}{l}71 / 18524 \\
\text { NCTC } 8509\end{array}$ & $\begin{array}{l}84 / 85 \\
6 / 42 E / 47 / 53 / 54 / 75 / 77 / \\
83 A / 84 / 85 / 81 / 42 D\end{array}$ & $\begin{array}{l}\text { PSTEFBNSuTM } \\
\text { None }\end{array}$ & $\begin{array}{l}8 \\
0 \cdot 25\end{array}$ \\
\hline
\end{tabular}

Table Summary of characters of strains used

1Resistant to: $\mathbf{P}=$ penicillin, $\mathbf{S}=$ streptomycin, $\mathrm{T}=$ tetracycline. $\mathrm{E}=$ erythromycin, $\mathrm{F}=$ fucidin, $\mathrm{B}=\mathbf{b a c i t r a c i n}, \mathbf{N}=$ neomycin, $\mathrm{Su}=$ sulphonamide, $\mathbf{T M}=$ trimethoprim

Propagating strain for typing phage 6 in the basic set 


\section{SENSITIVITY TESTING}

Drug sensitivity was determined by the disc diffusion method by means of Oxoid Multodisks (code numbers 11-14C and 1678E) and of single discs (Mast Laboratories, Liverpool, England) containing $2.5 \mu \mathrm{g}$ of trimethoprim and $50 \mu \mathrm{g}$ of sulphamethoxazole per disc. Oxoid nutrient agar (Oxoid nutrient broth no 2, code no. CM7, solidified with $1 \%$ Oxoid agar no. 3, code no. L13) was used for the tests except those with trimethoprim and sulphamethoxazole. Wellcotest sensitivity agar (WSA; Wellcome Reagents, Ltd) was used for disc diffusion tests with the latter two drugs and for determining the minimum inhibitory concentration (MIC) of trimethoprim by an agar incorporation method (Nakhla, 1972).

\section{TRANSDUCTION}

Phage 84 (NCTC no. 10454) of the basic set of staphylococcal typing phages was used in the transduction experiments. It was propagated in lytic cycle on strain $71 / 18524$, the trimethoprim-resistant donor strain. Stationary-phase broth cultures of the recipient, propagating strain (PS6), containing 1-2 $\times$ $10^{8}$ viable units per $\mathrm{ml}$, were mixed with sufficient phage to give a multiplicity of infection of approximately $0 \cdot 1$. The same volume of recipient cells without phage was included in each experiment as a control. Sterile $\mathrm{CaCl}_{2}$ was added in solution so as to give a final concentration of $400 \mu \mathrm{g}$ per $\mathrm{ml}$. The mixture was incubated with gentle stirring in a water bath at $37^{\circ} \mathrm{C}$ for 20 minutes. It was then centrifuged, the supernatant discarded, and the deposit suspended in broth containing $2 \times 10^{-2} \mathrm{M}$ sodium citrate to prevent further phage adsorption. Incubation was continued for three hours. The cells were then recovered by centrifugation and washed once in sterile physiological saline. This was done to remove as far as possible the metabolites remaining from the culture medium, which might have permitted trimethoprim-sensitive recipients to grow in the presence of this drug. The cells were suspended in a small volume of physiological saline and spread on plates of WSA containing $5 \mu \mathrm{g}$ per $\mathrm{ml}$ of trimethoprim. Plates were incubated at $37^{\circ} \mathrm{C}$ for $42 \mathrm{hr}$ and then examined for transductants.

In some experiments, the transducing phage was irradiated with ultraviolet light. Petri dishes containing $5 \mathrm{ml}$ of phage suspension in nutrient broth were placed at a distance of $10 \mathrm{~cm}$ from the ultraviolet source, a Honovia Chromatolite lamp (90\% of output at wavelength $254 \mathrm{~nm}$ ). After irradiation for two, four, six, eight, 10, 12 min samples were removed, titrated for survivors, and used in transduction experiments.

The frequency of transduction was calculated as the ratio of the number of transductants isolated to the number of active phage particles used in the experiments. When ultraviolet phage was used, it was calculated on the number of active particles present before inactivation and not on the number of particles surviving the inactivating dose.

\section{STABILITY OF TRANSDUCED RESISTANCE}

The stability of trimethoprim resistance was tested by the ability of the transductants to lose their acquired resistance after growth at $43^{\circ} \mathrm{C}$ (Asheshov, 1966) in the presence of $12.5 \mu \mathrm{g}$ per $\mathrm{ml}$ of 5 -aminoacridine hydrochloride (Hashimoto et al, 1964) and of $6 \times 10^{-6}$ M-ethidium bromide (Rubin and Rosenblum, 1970). The methods used by the respective authors were adopted.

\section{Results}

\section{TRANSDUCTION OF TRIMETHOPRIM} RESISTANCE

Trimethoprim-resistant transductants of PS6 were obtained in each of several experiments. Twenty-four transductants from each experiment were purified by streaking on trimethoprim-containing WSA medium, and their identity was confirmed by determining their phage-typing and antibiotic-resistance patterns. They were resistant to trimethoprim but sensitive to all the other antibiotics to which the donor strain was resistant. They showed the same degree of resistance to trimethoprim as did the donor (MIC: $8 \mu \mathrm{g}$ per $\mathrm{ml}$ ).

The frequency of transduction with irradiated

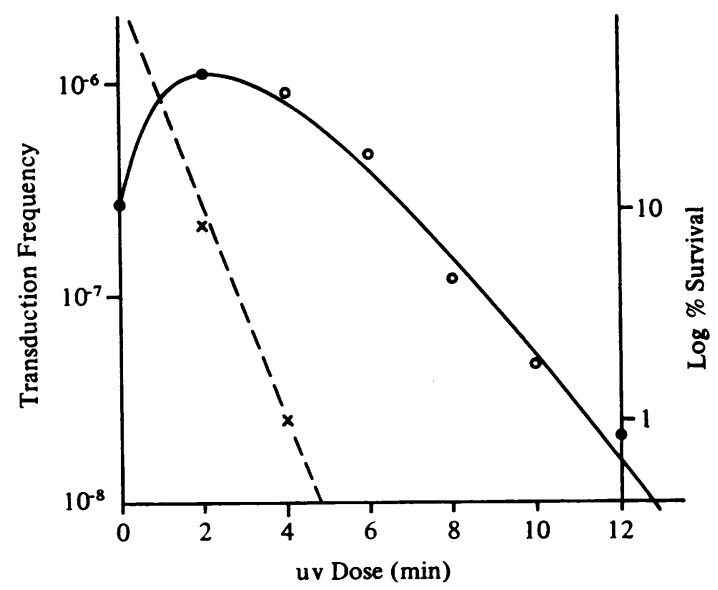

Fig Frequency of transduction of trimethoprim resistance plotted as a function of dose of ultraviolet given to the transducing phage. $\bigcirc-\bigcirc$ transduction frequency; $\times \ldots \ldots$ - $\times$ survivors after ultraviolet. 
phage was low $\left(2.7 \times 10^{-7}\right)$ but increased 4.5 -fold when the transducing phage was given a small dose of ultraviolet irradiation (figure). This response to irradiation is typical for transduction of chromosomal genes (Arber, 1960). A few resistant clones were isolated from the control cultures in each experiment. Their number, which did not exceed 10 in any one experiment, was at least 10 times less than the number of transductants obtained. They were presumed to result from spontaneous mutation in the recipient culture and showed the same degree of resistance as the donor strain (MIC: $8 \mu \mathrm{g}$ per $\mathrm{ml}$ ).

\section{STABILITY OF TRIMETHOPRIM RESISTANCE}

Resistant transductants of PS6 were examined for loss of resistance after growth at $43^{\circ} \mathrm{C}$ for $48 \mathrm{hr}$ and after growth in the presence of 5-aminoacridine hydrochloride (12.5 $\mu \mathrm{g}$ per $\mathrm{ml}$ ) and ethium bromide $\left(6 \times 10^{-6} \mathrm{M}\right)$. No sensitive clones were found among 1000-2000 examined in each of these experiments.

\section{Discussion}

The genetic determinants for trimethoprim resistance in strain 71/18524 could be transduced to PS6. The kinetics of transduction, in particular the stimulation in the frequency of transduction by small doses of ultraviolet irradiation given to the transducing phage, suggest a chromosomal rather than a plasmid location for the resistance determinants (Arber, 1960; Asheshov, 1969; Novick, 1969). Further support for this view was provided by the finding that trimethoprim resistance was a stable character. Sensitive mutants could not be detected after growth at an elevated temperature or in the presence of the intercalating dyes, 5-aminoacridine $\mathrm{HCl}$ or ethidium bromide, treatments that are known to cause irreversible loss of plasmid in Staph. aureus (Hashimoto et al, 1964; May, Houghton, and Perret, 1964; Bouanchaud, Scavizzi, and Chabbert, 1969; Rubin and Rosenblum, 1970, 1971).

Although the donor strain was resistant to several antibiotics, co-transduction of other drug-resistance markers was not observed. Resistance to sulphonamides and to trimethoprim, drugs which act on sequential steps in the folate biosynthetic pathway, may be controlled by closely linked genes. However, no evidence of close linkage was demonstrated in these experiments.

Transfer of antibiotic-resistance markers between strains of staphylococci in mixed cultures has been shown to occur, both when the genetic determinants are carried on a plasmid (Novick and Morse, 1967; Lacey, 1971a and b) or on the chromosome (Lacey, 1972). Transfer appears to be by transduction medi- ated by temperate phage carried by the donor strain Mixed culture experiments as described by Lacey. (1972) were tried in the present work to determin the possibility of transfer of trimethoprim resistance under these conditions but the results were incono clusive.

It is uncertain whether the transfer of trimetho prim-resistance determinants between strains wils have an important influence on the frequency of this resistance in staphylococci. In view of the fact that some degree of spontaneous mutation to resistance occurs as revealed in the transduction experiments $\omega_{\sigma}$ it may not be necessary to invoke transduction toक explain the appearance of resistant strains in hospitals. As with the Gram-negative bacilli(Darrelp et al, 1968), mutation to resistance, with or without the transfer of resistance between strains, may be expected to lead to further increases in the frequencyo of trimethoprim resistance among staphylococci if $\mathrm{co}_{-}^{-}$ trimoxazole continues to be used at the present rate $\vec{c}$ That the naturally occurring trimethoprim-resistan $\mathbb{D}^{\mathbb{C}}$ staphylococci so far encountered in London hospitals have all been resistant to sulphonamides and to several other antibiotics, and that the sulphonamide resistance is very freqent among multiple resistant strains found in the hospital population (Nakhfa, $\omega^{-1}$ 1972) suggest that the widespread use of co-trim oxazole may cause an increase in the prevalence $\overline{3}$ po undesirable strains with a wide pattern of resistances to antimicrobial agents.

I am indebted to Dr E. H. Asheshov for advice and $\stackrel{\varrho}{\rightarrow}$ suggestions.

References

Arber, W. (1960). Transduction of chromosomal genes and episomes in Escherichia coli. Virology, 11, 273-288.

Asheshov, E. H. (1966). Loss of antibiotic resistance in Staphylococcus aureus resulting from growth at high temperature. J. gen.?
Microbiol., 42, 403-410.

Asheshov, E. H. (1969). The genetics of penicillinase production in Staphylococcus aureus strain PS80. J. gen. Microbiol., 59, 289-윽

Bouanchaud, D. H., Scavizzi, M. R., and Chabbert, Y. A. (1969). $D$ Elimination by ethidium bromide of antibiotic resistance in

Darrell, J. H., Garrod, L. P., and Waterworth, P. M. (1968). Trimetho- N prim: laboratory and clinical studies. J. clin. Path., 21, 202-209.

Hashimoto, M, Kono, K., and Mitsuhashi, S. (1964). Elimination of $\mathrm{N}$ penicillin resistance of Staph. aureus by treatment with acriflavin. J. Bact., 88, 261-262. Lacey, R. W. (1971a). High frequency transfer of neomycin resistance $\frac{\omega}{\sigma}$
between naturally occurring strains of Staphylococcus aureus

in mixed cultures. J. med. Microbiol., 4, 73-84.
Lacey, R. W. (1971b). Transfer of tetracycline resistance between $\frac{\varrho}{(D)}$ strains of Staphylococcus aureus in mixed cultures. J. gen. (D) Microbiol., 69, 229-237.

Lacey, R. W. (1972). Transfer of chromosomal genes between $\square$ staphylococci in mixed cultures. J. gen. Microbiol., 71, 399-401.

May, J. W., Houghton, R. H., and Perret, C. J. (1964). The effect of $\frac{\overrightarrow{+}}{+}$ growth at elevated temperatures on some heritable properties $\triangle$ of Staphylococcus aureus. J. gen. Microbiol., 37, 157-169. 
Nakhla, L. S. (1972). Resistance of Staphylococcus aureus to sulphamethoxazole and trimethoprim. J. clin. Path., 25, 708-712.

Novick, R. P. (1969). Extrachromosomal inheritance in bacteria. Bact. Rev., 33, 210-235.

Novick, R. P., and Morse, S. I. (1967) In vivo transmission of drug resistance factors between strains of Staphyloroccus aureus. J. exp. Med. 125, 45-59.
Rubin, S. J., and Rosenblum, E. D. (1970). Elimination of staphylococcal penicillinase plasmid by ethidium bromide. Bact. Proc., p. 61.

Rubin, S. J., and Rosenblum, E. D. (1971). Effects of ethidium bromide on growth and on loss of penicillinase plasmid of Staphylococcus aureus. J. Bact., 108, 1200-1204.

\section{Reports and Bulletins prepared by the Association of Clinical Biochemists}

The following reports and bulletins are published by the Association of Clinical Biochemists. They may be obtained from The Administrative Office, Association of Clinical Biochemists, 7 Warwick Court, Holborn, London, WC1R 5DP. The prices include postage, but air mail will be charged extra. Overseas readers should remit by British Postal or Money Order. If this is not possible the equivalent of $50 \mathrm{p}$ is the minimum amount that can be accepted.

\section{SCIENTIFIC REPORTS}

3 Automatic Dispensing Pipettes. An assessment of 35 commercial instruments 1967 P. M. G. BROUGHTON, A. H. GOWENLOCK, G. M. WIDDOWSON, and K. A. AHLQUIST 80p (\$2)

4 An Evaluation of five Commercial Flame Photometers suitable for the Simultaneous Determination of Sodium and Potassium March 1970 P. M. G. BROUGHTON and J. B. DAWSON $80 \mathrm{p}(\$ 2)$

\section{SCIENTIFIC REVIEWS}

1 The Assessment of Thyroid Function March 1971 F. V. FLYNN and J. R. HOBBS 60p (\$1.50)

2 Renal Function Tests Suitable for Clinical Practice January 1972 F. L. MITCHELl, N. VEALL, and R. W. E. WATTS $60 \mathrm{p}(\$ 1.50)$

TECHNICAL BULLETINS

9 Determination of Urea by AutoAnalyzer November 1966 RUTH M. HASLAM 40p (\$1)

11 Determination of Serum Albumin by AutoAnalyzer using Bromocresol Green October 1967 B. E. NORTHAM and G. M. WIDDOwson 40p (\$1)

13 An Assessment of the Technicon Type II Sampler Unit March 1968 B. C. GRAY and G. K. McGOWAN $40 \mathrm{p}(\$ 1)$

14 Atomic Absorption Spectroscopy. An outline of its principles and a guide to the selection of instruments May 1968 J. B. DAWSON and P. M. G. BROUGHTON 40p (\$1)

15 A Guide to Automatic Pipettes (2nd edition) June 1968 P. M. G. BROUGHTON 40p (\$1)

16 A Guide to Automation in Clinical Chemistry May 1969 P. M. G. BROUGHTON 60p (\$1.50)

17 Flame Photometers (2nd edition) 1969 P. WILDING $60 \mathrm{p}(\$ 1.50)$
19 Spectrophotometers. A comparative list of low-priced instruments readily available in Britain May 1970 C. E. WILDE and P. SEWELL 60p (\$1.50)

20 Quantities and Units in Clinical Biochemistry June 1970 P. M. G. BROUGHTON 60p (\$1.50) More than 30 copies in units of 10 at $20 p$

21 Filter Fluorimeters: A comparative list of 18 instruments September 1970 H. BRAUNSBERG and $\mathrm{S}$. $\mathrm{S}$. BROWN 60p (\$1.50)

22 Bilirubin standards and the Determination of Bilirubin by Manual and Technicon AutoAnalyzer Methods January 1971 BARBARA BILLING, RUTH HASLAM, and N. WALD 60p (\$1.50)

23 Interchangeable Cells for Spectrophotometers and Fluorimeters September 1971 E. S. BROWN and A. H. GOWENLOCK 60p (\$1.50)

24 Simple Tests to Detect Poisons March 1972 B. w. MEADE et al. $\quad 60 \mathrm{p}(\$ 1.50)$

25 Blood Gas Analysers May 1972 K. DIXoN 60p $(\$ 1.50)$

26 Kits for Enzyme Activity Determination September 1972 S. B. ROSALKI and D. TARLOW 80p (\$2.00)

27 Assessment of Pumps Suitable for Incorporation into Existing Continuous Flow Analytical Systems November 1972 A. FLECK et al. 60p (\$1.50)

28 Routine Clinical Measurements of Transferrin in Human Serum September 1973 K. DIXON 60p (\$1.50)

29 Control Materials for Clinical Biochemistry (5th edition) September 1973 J. F. STEVENS 60p (\$1.50)

30 Notes on the Quality of Performance of Serum Cholesterol Assays September 1973 s. S. BROWN 60p $(\$ 1.50)$ 